Article

\title{
Bottom-Up Physiologically Based Oral Absorption Modeling of Free Weak Base Drugs
}

\author{
Naoya Matsumura ${ }^{1, *}$, Asami Ono ${ }^{2}$, Yoshiyuki Akiyama ${ }^{3}$, Takuya Fujita ${ }^{4}$ (D) and \\ Kiyohiko Sugano 5 (D)
}

1 Minase Research Institute, Ono Pharmaceutical Co., Ltd., 3-1-1 Sakurai, Shimamoto-cho, Mishima-gun, Osaka 618-8585, Japan

2 Laboratory for Chemistry, Manufacturing, and Control, Pharmaceuticals Production \& Technology Center, Asahi Kasei Pharma Corporation, 632-1 Mifuku, Izunokuni, Shizuoka 410-2321, Japan;

ono.ar@om.asahi-kasei.co.jp

3 Central Pharmaceutical Research Institute, Japan Tobacco Inc., 1-1 Murasaki-cho, Takatsuki, Osaka 569-1125, Japan; yoshiyuki.akiyama@jt.com

4 Laboratory of Molecular Pharmacokinetics, College of Pharmaceutical Sciences, Ritsumeikan University, 1-1-1 Noji-higashi, Kusatsu, Shiga 525-8577, Japan; fujita-t@ph.ritsumei.ac.jp

5 Molecular Pharmaceutics Lab., College of Pharmaceutical Sciences, Ritsumeikan University, 1-1-1 Noji-higashi, Kusatsu, Shiga 525-8577, Japan; suganok@fc.ritsumei.ac.jp

* Correspondence: na.matsumura@ono.co.jp; Tel.: +81-75-961-1151; Fax: +81-75-962-9314

Received: 29 July 2020; Accepted: 27 August 2020; Published: 3 September 2020

check for updates

\begin{abstract}
In this study, we systematically evaluated "bottom-up" physiologically based oral absorption modeling, focusing on free weak base drugs. The gastrointestinal unified theoretical framework (the GUT framework) was employed as a simple and transparent model. The oral absorption of poorly soluble free weak base drugs is affected by gastric $\mathrm{pH}$. Alternation of bulk and solid surface $\mathrm{pH}$ by dissolving drug substances was considered in the model. Simple physicochemical properties such as $\mathrm{pK}_{\mathrm{a}}$, the intrinsic solubility, and the bile micelle partition coefficient were used as input parameters. The fraction of a dose absorbed $(\mathrm{Fa})$ in vivo was obtained by reanalyzing the pharmacokinetic data in the literature (15 drugs, a total of $85 \mathrm{Fa}$ data). The AUC ratio with/without a gastric acid-reducing agent (AUCr) was collected from the literature (22 data). When gastric dissolution was neglected, Fa was underestimated (absolute average fold error $(\mathrm{AAFE})=1.85$, average fold error $(\mathrm{AFE})=0.64)$. By considering gastric dissolution, predictability was improved (AAFE $=1.40, \mathrm{AFE}=1.04$ ). AUCr was also appropriately predicted $(\mathrm{AAFE}=1.54$, AFE $=1.04)$. The Fa values of several drugs were slightly overestimated (less than 1.7-fold), probably due to neglecting particle growth in the small intestine. This modeling strategy will be of great importance for drug discovery and development.
\end{abstract}

Keywords: free base; gastric dissolution; permeability; solubility; oral absorption; modeling

\section{Introduction}

Recent drug candidates show poor solubility in aqueous media [1]. Because the oral absorption of a drug is affected by its solubility in the gastrointestinal (GI) tract, poorly soluble drugs often show incomplete, variable, and less than dose-proportional oral absorption. Therefore, it is important to accurately evaluate the oral absorption of a drug candidate at the preclinical stage and design a formulation suitable for clinical studies [2]. The oral absorption of poorly soluble drugs is susceptible to various physiological conditions in the GI tract, such as gastric $\mathrm{pH}$, intestinal $\mathrm{pH}$, buffer capacity, bile micelle concentration, gastrointestinal transit time, and hydrodynamics [3-5]. In the case of poorly soluble weak base drugs, gastric dissolution can have a marked impact on their oral absorption. Drug-drug interactions (DDI) with gastric acid-reducing agents (ARA), such as antacids, $\mathrm{H}_{2}$ blockers, 
and proton pump inhibitors, are of great clinical importance, as they could reduce the efficacy of a drug by interfering with gastric dissolution [6-8]. In addition, elderly subjects tend to be achlorhydric [9,10].

Physiologically based pharmacokinetic (PBPK) modeling has been anticipated to be a powerful tool to improve the productivity of drug discovery and development [11]. There have been many case studies of oral absorption PBPK modeling [12-16]. However, case studies are prone to publication bias. Therefore, systematic evaluation is required to avoid publication bias. In addition, case-by-case parameter fitting has been widely used in most of these publications. The simulation process should be standardized when evaluating the predictability of a model $[17,18]$. Publication bias and case-by-case parameter fitting reduce the reliability of the prediction model [19]. Recently, a commercial software product was systematically evaluated regarding ARA DDI prediction for weak base drugs [20]. The results suggest that scientific knowledge in this area is still premature (Figures 4 and 5 in [20]). In that study, free and salt forms were not differentiated as drug substances. However, free and salt forms exhibit completely different dissolution mechanisms.

In the stomach, free weak base drugs are dissolved by gastric acid. However, the dissolution rate becomes relatively slow because the acidity is neutralized by the dissolving free bases at the solid surface (discussed in detail in the theory section) [21-24]. Some portion of the particles remain undissolved in the stomach and reach the small intestine. These particles serve as seed particles for particle growth, which reduces the drug concentration in the small intestine $[25,26]$. On the other hand, in the case of salt forms, the dissolution rate is predominantly determined by the solubility product $\left(\mathrm{K}_{\mathrm{sp}}\right)$ [27]. In addition, the nucleation of free base particles occurs before starting precipitation in the small intestine [28]. However, there are many unknown factors in the nucleation process [29-33].

In this study, we systematically evaluated an oral absorption PBPK model for poorly soluble weak base drugs, focusing on the free forms for the first time. To the best of our knowledge, there has been no systematically validated model for weak base drugs. The gastrointestinal unified theoretical framework (the GUT framework) was employed as a simple and transparent model. Previously, the GUT framework has been systematically validated for neutral and acidic drugs by the consortium of biopharmaceutical tools (CoBiTo) in Japan $[34,35]$. The model equations and physiological parameters of the GUT framework have been fully disclosed and well documented in the literature [5,34-36]. In this study, a simple approximate analytical solution that describes the gastric dissolution processes of free weak base drugs was introduced to the GUT framework. The fraction of a dose absorbed $(\mathrm{Fa})$ and the ARA effect were predicted from simple input parameters such as $\mathrm{pK}_{\mathrm{a}}$, the octanol-water partition coefficient $\left(\log \mathrm{P}_{\mathrm{oct}}\right)$, and the biorelevant solubility, in a fully "bottom-up" manner.

\section{Theory}

\subsection{Solubility in the Stomach}

Gastric fluid is acidified by hydrochloric acid $(\mathrm{HCl})$. Because $\mathrm{HCl}$ is not an efficient buffer, the $\mathrm{pH}$ value increases when a free weak base drug is added to the gastric fluid [37]. The equilibrium $\mathrm{pH}$ value after the addition of an excess amount of a free weak base drug $\left(\mathrm{pH}_{\mathrm{eq}}\right)$ can be calculated as follows. From charge neutrality at equilibrium,

$$
\left[\mathrm{H}^{+}\right]+\left[\mathrm{BH}^{+}\right]=\left[\mathrm{Cl}^{-}\right]+\left[\mathrm{OH}^{-}\right]
$$

where $B$ is a free base drug. From the definition of the dissociation constant $\left(K_{a}\right)$ and the water ion product constant $\left(\mathrm{K}_{\mathrm{W}}\right)$,

$$
\begin{gathered}
\mathrm{K}_{\mathrm{a}}=\frac{\left[\mathrm{H}^{+}\right][\mathrm{B}]_{\mathrm{sat}}}{\left[\mathrm{BH}^{+}\right]}=\frac{\left[\mathrm{H}^{+}\right] \mathrm{S}_{0}}{\left[\mathrm{BH}^{+}\right]} \\
\mathrm{K}_{\mathrm{w}}=\left[\mathrm{H}^{+}\right]\left[\mathrm{OH}^{-}\right]
\end{gathered}
$$


where $S_{0}$ is the intrinsic solubility of a free base drug $\left(=[B]_{\text {sat }}\right)$. The $S_{0}$ value can be back-calculated from the buffer solubility and $\mathrm{pK}_{\mathrm{a}}$. From charge neutrality in an initial $\mathrm{HCl}$ solution,

$$
\left[\mathrm{Cl}^{-}\right]+\left[\mathrm{OH}^{-}\right]_{\text {ini }}=\left[\mathrm{H}^{+}\right]_{\text {ini }}
$$

where $\left[\mathrm{H}^{+}\right]_{\text {ini }}$ is the initial proton concentration that can be calculated from the initial gastric $\mathrm{pH}$ $\left(\mathrm{pH}_{\text {STini }}\right)$. By inserting Equations (2) to (4) into Equation (1),

$$
\left[\mathrm{H}^{+}\right]+\frac{\left[\mathrm{H}^{+}\right] \mathrm{S}_{0}}{\mathrm{~K}_{\mathrm{a}}}=\left[\mathrm{H}^{+}\right]_{\text {ini }}-\frac{\mathrm{K}_{\mathrm{w}}}{\left[\mathrm{H}^{+}\right]_{\text {ini }}}+\frac{\mathrm{K}_{\mathrm{w}}}{\left[\mathrm{H}^{+}\right]}
$$

this equation can be rearranged to a quadratic equation of $\left[\mathrm{H}^{+}\right]$.

$$
\left[\mathrm{H}^{+}\right]^{2}\left(1+\frac{\mathrm{S}_{0}}{\mathrm{~K}_{\mathrm{a}}}\right)-\left[\mathrm{H}^{+}\right]\left(\left[\mathrm{H}^{+}\right]_{\mathrm{ini}}-\frac{\mathrm{K}_{\mathrm{w}}}{\left[\mathrm{H}^{+}\right]_{\text {ini }}}\right)-\mathrm{K}_{\mathrm{w}}=0
$$

By solving this equation, the equilibrium $\mathrm{pH}$ value $\left(\mathrm{pH}_{\mathrm{eq}}\right)$ can be calculated. From $\mathrm{pH}_{\mathrm{eq}}$ and the Henderson-Hasselbalch equation, the maximum solubility of a free weak base drug in the stomach $\left(\mathrm{S}_{\mathrm{ST}}\right)$ can be calculated as,

$$
\mathrm{S}_{\mathrm{ST}}=\mathrm{S}_{0}\left(1+\frac{\left[\mathrm{H}^{+}\right]_{\mathrm{eq}}}{\mathrm{K}_{\mathrm{a}}}\right)
$$

where $\left[\mathrm{H}^{+}\right]_{\text {eq }}$ is the proton concentration of the solution in equilibrium with a free weak base drug.

The dose number in the stomach (DosT) is defined as,

$$
\operatorname{Do}_{\mathrm{ST}}=\frac{\text { Dose }}{\mathrm{S}_{\mathrm{ST}} \mathrm{V}_{\mathrm{ST}}}
$$

where Dose is the dose amount and $\mathrm{V}_{\mathrm{ST}}$ is the gastric fluid volume.

\subsection{Dissolution Rate in the Stomach}

In the case of free weak base drugs, solid surface $\mathrm{pH}\left(\mathrm{pH}_{\text {surface }}\right)$ becomes higher than bulk $\mathrm{pH}$. The $\mathrm{pH}_{\text {surface }}$ value can be calculated using the Mooney-Stella equation [21-24]. The solid surface solubility $\left(\mathrm{S}_{\text {surface, }} \mathrm{ST}\right)$ can be calculated from $\mathrm{pH}_{\text {surface }}$ and $\mathrm{S}_{0}$, similar to Equation (7). The dissolution rate coefficient in the stomach $\left(\mathrm{k}_{\mathrm{diss}} \mathrm{ST}\right)$ can be calculated as,

$$
\mathrm{k}_{\text {diss }, \mathrm{ST}}=\frac{3 \mathrm{DS}_{\text {surface }, \mathrm{ST}}}{\rho} \sum \frac{\mathrm{i}}{\mathrm{f}_{\mathrm{i}}}
$$

where $\mathrm{D}_{\mathrm{ST}}$ is the diffusion coefficient in the gastric fluid, $\rho$ is the true density of a drug substance (set to $\left.1.2 \mathrm{~g} / \mathrm{cm}^{3}\right), f_{i}$ is the fraction of a drug amount in a particle size bin (i), and $r_{p, i}$ is the initial particle radius. The particle size distribution was assumed to have a log-normal distribution with $\ln 2$ standard deviation. The diffusion coefficient of a monomer drug molecule is calculated as,

$$
\mathrm{D}\left(\mathrm{cm}^{2} / \mathrm{s}\right)=9.9 \times 10^{-5} \mathrm{MW}^{-0.453}
$$

The dissolution number in the stomach $\left(\mathrm{Dn}_{\mathrm{ST}}\right)$ can be calculated as,

$$
\mathrm{Dn}_{\mathrm{ST}}=\mathrm{k}_{\mathrm{diss}, \mathrm{ST}} \cdot \mathrm{T}_{\mathrm{ST}}
$$

where $\mathrm{T}_{\mathrm{ST}}$ is the gastric transit time. 


\subsection{Fraction Dissolved in the Stomach}

The fraction dissolved in the stomach $\left(\mathrm{Fd}_{\mathrm{ST}}\right)$ for the solubility-limited (SL) and the dissolution rate-limited (DRL) cases can be calculated as,

$$
\begin{gathered}
\mathrm{Fd}_{\mathrm{ST}}(\text { for SL })=\frac{1}{\mathrm{Do}_{\mathrm{ST}}} \\
\mathrm{Fd}_{\mathrm{ST}}(\text { for DRL })=\frac{\mathrm{k}_{\mathrm{diss}, \mathrm{ST}}}{\mathrm{k}_{\mathrm{diss}, \mathrm{ST}}+\mathrm{k}_{\mathrm{tr}, \mathrm{ST}}}=\frac{1}{1+\frac{\mathrm{k}_{\mathrm{tr}, \mathrm{ST}}}{\mathrm{k}_{\mathrm{diss}, \mathrm{ST}}}=\frac{1}{1+\frac{1}{\mathrm{Dn}_{\mathrm{ST}}}}}
\end{gathered}
$$

where $\mathrm{k}_{\mathrm{tr}, \mathrm{ST}}$ is the gastric transit rate constant $\left(=1 / \mathrm{T}_{\mathrm{ST}}\right)$. From Equations (12) and (13), an approximate solution for $\mathrm{Fd}_{\mathrm{ST}}$ for general cases can be derived as,

$$
\mathrm{Fd}_{\mathrm{ST}}=\frac{1}{\mathrm{Do}_{\mathrm{ST}}+1+\frac{1}{\mathrm{Dn}_{\mathrm{ST}}}}
$$

\subsection{Calculation of the Fraction of a Dose Absorbed Considering Gastric Dissolution}

This study hypothesized that drug molecules dissolved in the stomach would not rapidly precipitate in the small intestine before absorption (the validity of this assumption is discussed later). In addition, drug absorption from the stomach was assumed to be negligible. In this case, the fraction of a dose absorbed ( $\mathrm{Fa})$ attributed to gastric dissolution $\left(\mathrm{Fa}_{\mathrm{FdST}}\right)$ becomes

$$
\mathrm{Fa}_{\mathrm{FdST}}=\mathrm{Fd}_{\mathrm{ST}}\left(1-\exp \left(-\mathrm{Pn}_{\mathrm{SI}}\right)\right)
$$

where $\mathrm{Pn}_{\mathrm{SI}}$ is the permeation number in the small intestine. The total Fa is the sum of Fa FdST and the fraction of a dose absorbed in the small intestine attributed to drug dissolution in the small intestine ( $\left.\mathrm{Fa}_{\mathrm{SI}}\right)$.

$$
\mathrm{Fa}=\mathrm{Fa}_{\mathrm{FdST}}+\left(1-\mathrm{Fd}_{\mathrm{ST}}\right) \mathrm{Fa}_{\mathrm{SI}}
$$

FasI can be calculated by the Fa equation as [4,38],

$$
\text { FasI }_{S I}=1-\exp \left(-\frac{1}{\frac{1}{\operatorname{Dn}_{\mathrm{SI}}}+\frac{\mathrm{Do}_{\mathrm{SI}}}{\mathrm{Pn}_{\mathrm{SI}}}} \operatorname{Tn}_{\mathrm{SI}}\right) \text { if Do } \operatorname{Do}_{\mathrm{SI}}<1 \text {, set DosI }=1
$$

where $\mathrm{Do}_{\mathrm{SI}}$ is the dose number, $\mathrm{Dn}_{\mathrm{SI}}$ is the dissolution number, and $\mathrm{Tn}_{\mathrm{SI}}$ is the transit time number in the small intestine. The Dosi value is calculated from the undissolved drug amount reaching the small intestine (Dose $\left(1-\mathrm{Fd}_{\mathrm{ST}}\right)$ ). The details of FasI calculation have been well documented in the literature and are summarized in Supplementary Material 1. Even though dynamic simulations can also be performed by the GUT framework [26], to improve the transparency of the calculation processes, the Fa equation is used in this study. The contribution of gastric dissolution on $\mathrm{Fa}\left(\mathrm{Fa}_{\mathrm{FdST}} \%\right)$ is calculated as $\mathrm{Fa}_{\mathrm{FdST}} / \mathrm{Fa} \times 100$.

To evaluate the effect of gastric dissolution, Fa was predicted by the following three scenarios regarding gastric dissolution:

(A) No gastric dissolution

(B) Using bulk pH

(C) Using $\mathrm{pH}_{\text {surface }}$ and $\mathrm{pH}_{\mathrm{eq}}$.

In the case of $(\mathrm{A}), \mathrm{Fd}_{\mathrm{ST}}$ was set to 0 (so that $\mathrm{Fa}=\mathrm{Fa}$ ). In the case of $(\mathrm{B})$, the initial gastric $\mathrm{pH}\left(\mathrm{pH}_{\mathrm{ini}}\right)$ in Table 1 was used instead of $\mathrm{pH}_{\mathrm{eq}}$ in the $\mathrm{S}_{\mathrm{ST}}$ calculation (Equation (7)). In addition, $\mathrm{S}_{\text {surface,ST }}$ was set equal to $S_{\mathrm{ST}}$. In the case of $(\mathrm{C}), \mathrm{pH}_{\mathrm{eq}}$ and $\mathrm{S}_{\mathrm{ST}}$ were calculated from $\mathrm{S}_{0}, \mathrm{pK}_{\mathrm{a}}$, and $\mathrm{pH}_{\text {ini }}($ Equations (1) to (7)). $\mathrm{pH}_{\text {surface }}$ was calculated by the Mooney-Stella equation from $\mathrm{S}_{0}, \mathrm{pK}_{\mathrm{a}}$, the diffusion coefficient of a drug 
(D, Equation (10)), and $\mathrm{pH}_{\text {ini }}$. $\mathrm{S}_{\text {surface, } \mathrm{ST}}$ was then calculated from $\mathrm{S}_{0}, \mathrm{pK}_{\mathrm{a}}$, and $\mathrm{pH}_{\text {surface }}$. This was a fully bottom-up prediction; therefore, no parameter fitting was performed based on in vivo data.

Table 1. Physiological parameters.

\begin{tabular}{|c|c|c|c|c|}
\hline \multirow{2}{*}{ Parameters } & \multicolumn{2}{|c|}{ Human } & \multicolumn{2}{|c|}{ Dog } \\
\hline & Fasted & Fed & Fasted & Fed \\
\hline Stomach ${ }^{1}$ & & & & \\
\hline Initial gastric $\mathrm{pH}, \mathrm{pH}_{\mathrm{STini}}$ (normal/ with $\mathrm{ARA}$ ) & $2.0 / 6.0$ & $2.7 / 6.0$ & $2.0 / 6.0$ & $2.0 / 6.0$ \\
\hline Gastric emptying half-life, $\mathrm{T}_{\mathrm{ST} 1 / 2}(\mathrm{~min})^{2}$ & 10 & 60 & 10 & 180 \\
\hline Gastric fluid volume, $\mathrm{V}_{\mathrm{ST}}(\mathrm{mL})$ & 125 & 250 & 50 & 250 \\
\hline Small intestine ${ }^{3}$ & & & & \\
\hline Small intestinal $\mathrm{pH}$ & 6.5 & 6.0 & 7.0 & 6.0 \\
\hline Small intestinal bile micelle concentration, $\mathrm{C}_{\mathrm{bm}}(\mathrm{mM})$ & 3.0 & 15 & 5.0 & 18 \\
\hline Small intestinal transit time, $\mathrm{T}_{\mathrm{SI}}(\mathrm{min})$ & 210 & 210 & 120 & 120 \\
\hline Small intestinal fluid volume, $\mathrm{V}_{\mathrm{SI}}(\mathrm{mL})$ & 130 & 156 & 19 & 22 \\
\hline Plicate expansion, PE & 3 & 3 & 1 & 1 \\
\hline Villi expansion, VE & 10 & 10 & 10 & 10 \\
\hline Radius of small intestine, $\mathrm{R}_{\mathrm{GI}}(\mathrm{cm})$ & 1.5 & 1.5 & 0.5 & 0.5 \\
\hline Degree of flatness, DF & 1.7 & 1.7 & 1.7 & 1.7 \\
\hline Paracellular radius, $\mathrm{R}_{\text {ParaMW }}$ & 8.46 & 8.46 & 12.9 & 12.9 \\
\hline Unstirred water layer thickness, $\mathrm{h}_{\mathrm{UWL}}(\mathrm{cm})$ & 0.03 & 0.03 & 0.03 & 0.03 \\
\hline Particle-drifting coefficient, $\mathrm{C}_{\mathrm{pd}}$ & 2.2 & 2.2 & 2.2 & 2.2 \\
\hline Nominal pore radius, $R_{\text {mucus }}(\mu \mathrm{m})$ & 2.9 & 2.9 & 2.9 & 2.9 \\
\hline
\end{tabular}

${ }^{1}$ References are cited in Supplementary Material $1 ;{ }^{2}$ Gastric transit time $\left(\mathrm{T}_{\mathrm{ST}}\right)=\mathrm{T}_{\mathrm{ST} 1 / 2} / \ln 2 ;{ }^{3}$ The same values used in the previous studies $[34,36]$. A detailed explanation of these parameters is provided in Supplementary Material 1.

The details of the calculation scheme and all intermediate values, including $\mathrm{pH}_{\mathrm{eq}}, \mathrm{pH}_{\text {surface }}, \mathrm{S}_{\mathrm{ST}}$, $\mathrm{S}_{\text {surface,ST, }}$, and the effective intestinal membrane permeability $\left(\mathrm{P}_{\text {eff }}\right)$, are provided in Supplementary Material 1.

\subsection{Fa Rate-Limiting Steps (FaRLS)}

The oral absorption of a drug can be categorized as permeability, dissolution rate, and solubilitypermeability limited cases (PL, DRL, and SL, respectively). Permeability can be further divided into epithelial membrane permeability-limited and unstirred water layer permeability-limited (-E and - $\mathrm{U}$, respectively). The criteria of FaRLS are summarized in Supplementary Material 1 Table S1. Similarly, the limiting factor of $\mathrm{Fd}_{\mathrm{ST}}$ was categorized as DRL or SL based on Equation (14).

\subsection{Physiological Parameters}

The physiological parameters are summarized in Table 1 . The gastric emptying half-life $\left(\mathrm{T}_{\mathrm{ST} 1 / 2}\right)$ values were set to 10 and $60 \mathrm{~min}$ for fasted and fed state humans [39-44], and 10 and $180 \mathrm{~min}$ for fasted and fed dogs [45-48], respectively. The time-averaged gastric fluid volume ( $\left.\mathrm{V}_{\mathrm{ST}}\right)$ was set to 125 and $250 \mathrm{~mL}$ for fasted and fed state humans, respectively, considering water and food intake with a drug and the gastric emptying of the stomach contents [39-41]. Similarly, the gastric fluid volume in fasted dogs was set to $50 \mathrm{~mL}$, considering water intake with a drug [49]. The gastric fluid volume in fed dogs has not been found in the literature. Therefore, the gastric fluid volume in fed dogs was assumed to be $250 \mathrm{~mL}$ as the size of the stomach is comparable to humans [50]. Dogs consume about 200-400 $\mathrm{g}$ of food once a day [51,52].

The gastric $\mathrm{pH}$ values were set to 2.0 and 2.7 for the fasted and fed state humans, respectively. It is well known that the gastric $\mathrm{pH}$ value temporarily increases to about $\mathrm{pH} 6$ after food intake. However, the $\mathrm{pH}$ value returns to acidic in $60-90 \mathrm{~min}$ due to postprandial gastric acid secretion $[10,53,54]$. Therefore, the gastric $\mathrm{pH}$ value at the mean gastric transit time was used for the fed state in humans ( $\mathrm{pH}$ 2.7). The gastric $\mathrm{pH}$ value in the fasted state ranges from $\mathrm{pH} 1.0$ to 2.4 in humans, with a mean 
value of about $\mathrm{pH} 1.5[10,54]$. The $\mathrm{pH}$ value would be slightly increased by water intake. Therefore, the gastric $\mathrm{pH}$ value in the fasted state was set to $\mathrm{pH}$ 2.0. The gastric $\mathrm{pH}$ value in dogs was set to $\mathrm{pH}$ 2.0 for both the fasted and fed states, respectively $[55,56]$. However, it should be noted that the gastric $\mathrm{pH}$ value in dogs shows a large variation [57-59]. The gastric $\mathrm{pH}$ value after the administration of PPI or $\mathrm{H}_{2}$ blockers was set to $\mathrm{pH} 6.0$ for both humans and dogs [60,61]. The small intestinal $\mathrm{pH}$ values in fasted and fed dogs were set to be 7.0 and 6.0, respectively [34,62]. The other physiological parameters of the small intestine were the same as used in the previous studies $[34,36]$.

\subsection{In Vivo Fa Data}

In vivo Fa values were calculated from the literature data. As there is no exact method to measure $\mathrm{Fa}$, one or a few approximations have been used to estimate Fa from in vivo PK data $[36,63]$.

(I) Fa described in the literature was used as it was.

(II) Relative bioavailability of solution vs. solid form formulation.

(III) Relative bioavailability in the fasted state vs. in the fed state (especially when $\mathrm{Do}_{\mathrm{SI}}<1$ in the fed state).

(IV) Relative bioavailability with the low vs. high $\mathrm{pH}$ stomach when $\mathrm{Do}_{\mathrm{SI}}<1$ in the stomach (for basic drugs) (not used in this study)

(V) Dose-normalized relative bioavailability at $\operatorname{Do}_{S I}<1$ vs. DosI $>1$ when the terminal elimination half-life is consistent.

(VI) From absolute bioavailability (F) and hepatic clearance using $\mathrm{Fa}=\mathrm{F} /(1-\mathrm{CLh} / \mathrm{Qh})$.

The methods (II)-(V) have been used because Fa can be assumed to be $100 \%$ when there are no solubility and dissolution rate limitations for lipophilic drugs $\left(\log \mathrm{D}_{\text {oct }}\right.$ at $\left.\mathrm{pH} 6.5>0.5\right)$ [5]. In the cases when multiple calculation methods could have been applied, these methods showed similar Fa values (within 0.8- to 1.3-fold difference in this study), suggesting that these methods are appropriate in most cases. The AUC ratio with/without ARA (AUCr) was also calculated from the literature data. Full references for in vivo Fa and AUCr are provided in Supplementary Material 2 Table S2. In addition to human Fa data, dog Fa data were also collected from the literature. Dogs have been used as a preclinical animal model for formulation studies $[51,64,65]$.

\subsection{Statistics}

The Fa predictability was evaluated by the absolute average fold error (AAFE), the average fold error (AFE), the coefficient of determination $\left(\mathrm{r}^{2}\right)$, and the percentage within twofold error. The absolute average fold error (AAFE) was calculated as,

$$
\mathrm{AAFE}=10^{\left(\frac{\sum\left|\log \left(\frac{\text { Predicted Fa }}{\text { Observed Fa }}\right)\right|}{\mathrm{n}}\right)}
$$

The AAFE converts negative log fold errors to positive values before averaging, measuring the spread of the predictions. The average fold error (AFE) was calculated as,

$$
\mathrm{AFE}=10^{\left(\frac{\sum \log \left(\frac{\text { Predicted Fa }}{\text { Observed Fa }}\right)}{\mathrm{n}}\right)}
$$

AFE indicates whether there is a trend for underprediction (AFE $<1$ ) or overprediction (AFE $>1)$.

\section{Results}

\subsection{Model Drugs}

An extensive literature survey was performed to collect in vivo Fa data of poorly soluble weak base drugs (free form). The Fa values of 15 drugs were calculated from the literature data (a total of $85 \mathrm{Fa}$ data). 
The majority of weak base drugs are launched as a salt form [27]. However, as mentioned in the introduction, the Fa prediction of salt form drugs is out of the scope of this study. The physicochemical properties of model drugs are shown in Table 2. The $\mathrm{pK}_{\mathrm{a}}$ and $\log \mathrm{P}_{\text {oct }}$ values ranged from 3.8 to 7.5 and -0.2 to 5.7 , respectively, covering the practical range of poorly soluble weak base drugs.

Table 2. Physicochemical properties of free weak base drugs.

\begin{tabular}{|c|c|c|c|c|c|c|c|}
\hline \multirow{2}{*}{ Drugs } & \multirow{2}{*}{ MW } & \multirow{2}{*}{$\mathrm{pK}_{\mathrm{a}}$} & \multirow{2}{*}{$\log P_{\text {oct }}$} & \multicolumn{3}{|c|}{ Solubility $(\mathrm{mg} / \mathrm{mL})$} & \multirow{2}{*}{ Ref. } \\
\hline & & & & Buffer ${ }^{3}$ & FaSSIF $^{4}$ & FeSSIF $^{4}$ & \\
\hline Acalabrutinib & 466 & 5.8 & 2.0 & $0.048(\mathrm{pH} 8.0)$ & $0.12^{5}$ & & {$[66]$} \\
\hline Albendazole & 265 & 4.2 & 3.1 & 0.0009 & 0.0021 & & {$[67,68]$} \\
\hline Aprepitant & 534 & 4.2 & 4.8 & 0.0008 & $0.019,0.021^{7}$ & 0.119 & [69-71] \\
\hline BMS & 550 & 6.3 & 2.3 & $0.019(\mathrm{pH} 6.6)$ & 0.043 & & {$[72]$} \\
\hline Cinnarizine & 369 & 7.5 & 5.7 & 0.0014 & 0.013 & 0.112 & [73] \\
\hline Danixirin & 442 & 4.8 & $1.2^{1}$ & $0.004(\mathrm{pH} 6.0)$ & 0.009 & & [74] \\
\hline Dasatinib & 488 & 6.8 & 3.2 & $0.01(\mathrm{pH} 6.0)$ & 0.032 & & {$[75,76]$} \\
\hline Dipyridamole & 505 & 4.9 & 3.9 & 0.006 & 0.017 & & {$[63,77]$} \\
\hline Enoxacin & 320 & 6.2 & $-0.2^{2}$ & 0.38 & $0.54^{5}$ & $0.83(\mathrm{pH} 5.8)^{5}$ & $\begin{array}{c}{[20,78,} \\
79]\end{array}$ \\
\hline Etoricoxib & 359 & 4.6 & 3.1 & 0.16 & 0.16 & & [80] \\
\hline Gefitinib & 447 & 7.2 & 4.1 & $0.002(\mathrm{pH} 6.9)$ & $0.085(\mathrm{pH} 6.4)$ & $2.0(\mathrm{pH} \mathrm{5.4)}$ & [81] \\
\hline Iburtinib & 441 & 3.8 & 4.0 & $0.0021(\mathrm{pH} 6.8)$ & $0.016(\mathrm{pH} 7.0)$ & & {$[82,83]$} \\
\hline Ketoconazole & 531 & 6.5 & 4.3 & 0.012 & 0.021 & & {$[63]$} \\
\hline Palbociclib & 448 & 7.4 & $1.3^{2}$ & $0.009(\mathrm{pH} \mathrm{7.9})^{6}$ & & & [84-86] \\
\hline Posaconazole & 701 & 4.6 & 5.4 & 0.0001 & 0.005 & & {$[87,88]$} \\
\hline \multicolumn{8}{|c|}{$\begin{array}{l}{ }^{1} \text { Calculated by ACD/logP (Advanced Chemistry Development, Inc.); }{ }^{2} \text { Enoxacin: Caco-2 } 6.4 \times 10^{-6} \mathrm{~cm} / \mathrm{s} \text { at } \\
\text { pH } 6.5 \text { [89]; Palbociclib: MDCK } 45 \times 10^{-6} \mathrm{~cm} / \mathrm{s} \text { at pH } 7.4 \text { [84]. These values were used for intrinsic permeability } \\
\text { calculation; }{ }^{3} \mathrm{pH} 6.5 \text { unless otherwise noted; }{ }^{4} \text { Fasted state simulated intestinal fluid (FaSSIF: taurocholic acid } 3 \mathrm{mM} \text {, } \\
\text { egg lecithin } 0.75 \mathrm{mM} \text {, pH 6.5). Fed state simulated intestinal fluid (FeSSIF: taurocholic acid } 15 \mathrm{mM} \text {, egg lecithin } \\
3.75 \mathrm{mM} \text {, pH 5.0). The solubility values in these fluids were used unless otherwise noted; }{ }^{5} \mathrm{FaSSIF} \text { v2: taurocholic acid } \\
3 \mathrm{mM} \text {, egg lecithin } 0.2 \mathrm{mM} \text {, pH 6.5, FeSSIF v2: taurocholic acid } 10 \mathrm{mM} \text {, egg lecithin } 2 \mathrm{mM}, \mathrm{pH} 5.8 \text { [90]; }{ }^{6} \text { The solubility } \\
\text { in the small intestine was estimated from } \mathrm{S}_{0} \text { and } \log \mathrm{P}_{\text {oct }} \text { (see Supplementary Material 1); }{ }^{7} \text { Dog FaSSIF: taurocholic } \\
\text { acid } 5 \mathrm{mM} \text {, egg lecithin } 1.25 \mathrm{mM} \text {, pH } 6.5 \text { [71]. }\end{array}$} \\
\hline
\end{tabular}

\subsection{Prediction Model}

Appropriate Fasi prediction is the prerequisite for predicting the Fa values of free weak base drugs. As mentioned in the introduction, prior to the present study, the GUT framework has been validated for predicting Fas in humans and dogs [34,35]. In these studies, neutral and free weak acid drugs were mainly used because the Fa values of these drugs are little affected by gastric dissolution $(\mathrm{Fa} \approx \mathrm{FasI})$. Structurally diverse drugs were employed in those studies (for example, 27 drugs with a total of 96 in vivo Fa values were employed in [35]). The GUT framework demonstrated the sufficient Fasi predictability necessary for the present study.

\subsection{Results of Fa Prediction}

The results of Fa prediction are shown in Table 3 and Figures 1 and 2. When gastric dissolution was neglected, the in vivo Fa values of free weak base drugs were markedly underestimated (Figure 1) (Table 4). By taking gastric dissolution into account, predictability was markedly improved. When the initial bulk pH was used to calculate gastric dissolution, the Fa values were overestimated. This overestimation was reduced by using $\mathrm{pH}_{\mathrm{eq}}$ and $\mathrm{pH}_{\text {surface }}$. The Fa values of posaconazole were exceptionally underestimated. When posaconazole was excluded, a slight overestimation was observed, even when $\mathrm{pH}_{\mathrm{eq}}$ and $\mathrm{pH}_{\text {surface }}$ were taken into account $(\mathrm{AFE}=1.15)$. 
Table 3. Dose, particle size, species, and food state for simulation and in vivo Fa data.

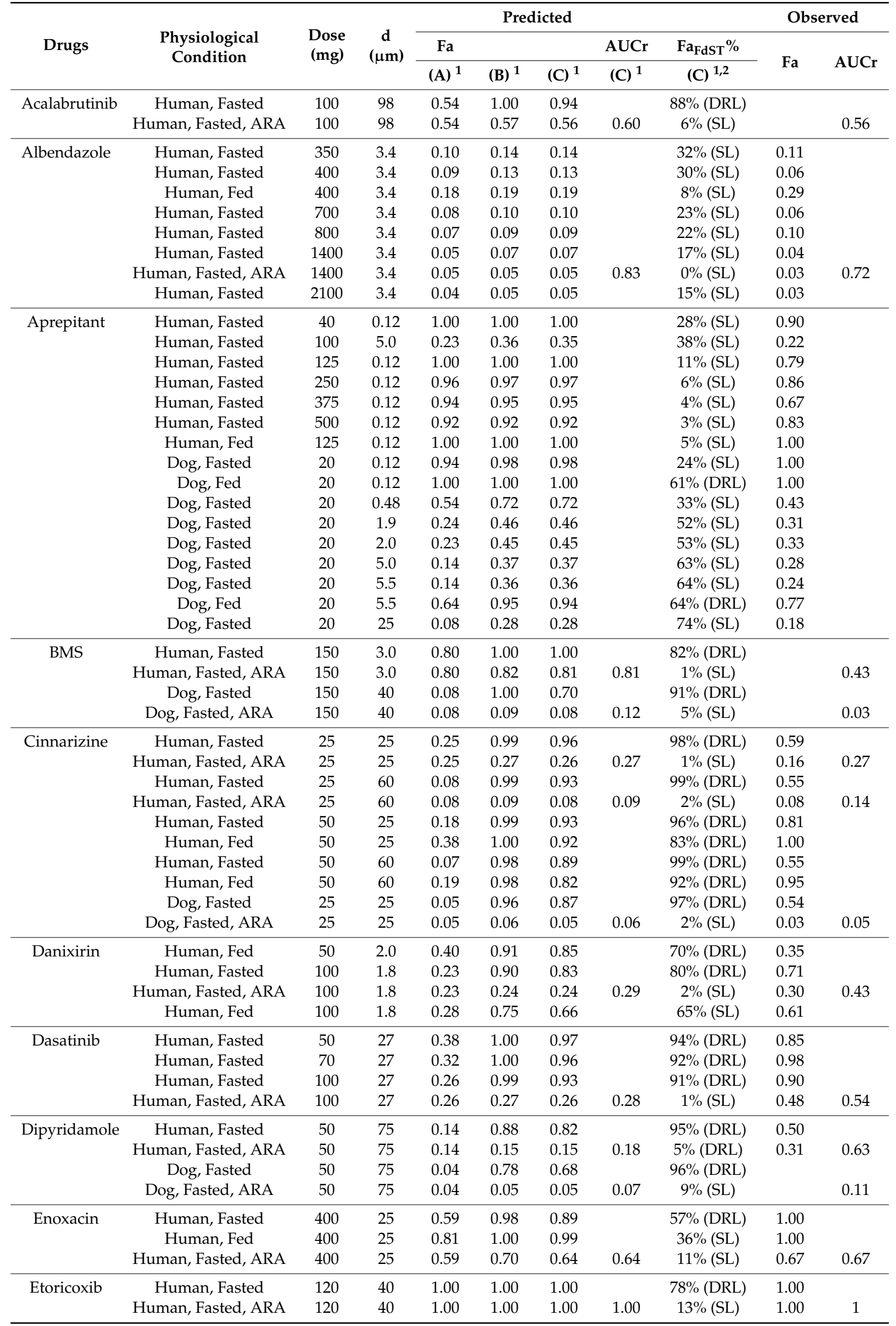


Table 3. Cont.

\begin{tabular}{|c|c|c|c|c|c|c|c|c|c|c|}
\hline \multirow{3}{*}{ Drugs } & \multirow{3}{*}{$\begin{array}{c}\text { Physiological } \\
\text { Condition }\end{array}$} & \multirow{3}{*}{$\begin{array}{l}\text { Dose } \\
\text { (mg) }\end{array}$} & \multirow{3}{*}{$\underset{(\mu \mathrm{m})}{\mathrm{d}}$} & \multicolumn{4}{|c|}{ Predicted } & \multicolumn{3}{|c|}{ Observed } \\
\hline & & & & $\mathbf{F a}$ & & & AUCr & $\mathrm{Fa}_{\mathrm{FdST}} \%$ & & \\
\hline & & & & (A) ${ }^{1}$ & (B) ${ }^{1}$ & (C) ${ }^{1}$ & (C) ${ }^{1}$ & (C) 1,2 & Fa & $\mathrm{AUCr}$ \\
\hline \multirow[t]{4}{*}{ Gefitinib } & Human, Fasted & 50 & 30 & 0.49 & 0.99 & 0.96 & & 94\% (DRL) & 0.74 & \\
\hline & Human, Fasted & 100 & 30 & 0.38 & 0.99 & 0.94 & & $89 \%$ (DRL) & 0.69 & \\
\hline & Human, Fasted & 250 & 30 & 0.23 & 0.99 & 0.81 & & $83 \%$ (DRL) & 0.78 & \\
\hline & Human, Fasted & 500 & 30 & 0.15 & 0.98 & 0.64 & & 81\% (DRL) & 0.80 & \\
\hline \multirow[t]{3}{*}{ Ibrutinib } & Human, Fasted & 560 & 10 & 0.10 & 0.13 & 0.13 & & $21 \%(S L)$ & 0.21 & \\
\hline & Human, Fasted, ARA & 560 & 10 & 0.10 & 0.10 & 0.10 & 0.80 & $0 \%(\mathrm{SL})$ & 0.18 & 0.87 \\
\hline & Human, Fed & 560 & 10 & 0.39 & 0.40 & 0.40 & & $3 \%(\mathrm{SL})$ & 0.30 & \\
\hline \multirow{6}{*}{ Ketoconazole } & Human, Fasted & 400 & 25 & 0.17 & 1.00 & 0.75 & & 83\% (DRL) & 0.92 & \\
\hline & Human, Fed & 400 & 25 & 0.42 & 1.00 & 0.74 & & $53 \%(\mathrm{SL})$ & 1.00 & \\
\hline & Human, Fasted & 800 & 25 & 0.14 & 0.99 & 0.57 & & $79 \%(S L)$ & 0.86 & \\
\hline & Human, Fed & 800 & 25 & 0.32 & 1.00 & 0.54 & & $45 \%(\mathrm{SL})$ & 0.87 & \\
\hline & Dog, Fasted & 200 & 25 & 0.06 & 0.99 & 0.62 & & 91\% (DRL) & & \\
\hline & Dog, Fasted, ARA & 200 & 25 & 0.06 & 0.07 & 0.06 & 0.10 & $3 \%(\mathrm{SL})$ & & 0.03 \\
\hline \multirow[t]{4}{*}{ Palbociclib } & Human, Fasted & 125 & 16 & 0.46 & 1.00 & 1.00 & & $82 \%$ (DRL) & 0.90 & \\
\hline & Human, Fasted, ARA & 125 & 16 & 0.46 & 0.58 & 0.47 & 0.47 & $2 \%(\mathrm{SL})$ & 0.47 & 0.52 \\
\hline & Human, Fed & 125 & 16 & 0.81 & 1.00 & 1.00 & & $64 \%$ (DRL) & 0.95 & \\
\hline & Human, Fed, ARA & 125 & 16 & 0.81 & 0.91 & 0.82 & 0.82 & $2 \%(\mathrm{SL})$ & 0.86 & 0.91 \\
\hline \multirow{9}{*}{ Posaconazole } & Human, Fasted, ARA & 400 & 1.7 & 0.06 & 0.06 & 0.06 & 0.84 & $0 \%(\mathrm{SL})$ & 0.09 & 0.66 \\
\hline & Human, Fed & 400 & 1.7 & 0.46 & 0.46 & 0.46 & & $1 \%(\mathrm{SL})$ & 0.52 & \\
\hline & Human, Fed & 800 & 1.7 & 0.37 & 0.37 & 0.37 & & $1 \%(\mathrm{SL})$ & 0.42 & \\
\hline & Human, Fed & 1200 & 1.7 & 0.31 & 0.32 & 0.32 & & $1 \%(\mathrm{SL})$ & 0.23 & \\
\hline & Dog, Fasted & 100 & 1.7 & 0.05 & 0.07 & 0.07 & & $26 \%(S L)$ & 0.11 & \\
\hline & Dog, Fed & 100 & 1.7 & 0.29 & 0.37 & 0.37 & & $24 \%$ (SL) & 0.40 & \\
\hline & Dog, Fed & 400 & 1.7 & 0.14 & 0.16 & 0.16 & & 15\% (SL) & 0.40 & \\
\hline & Dog, Fed & 800 & 1.7 & 0.08 & 0.10 & 0.10 & & $13 \%(\mathrm{SL})$ & 0.32 & \\
\hline & Dog, Fed & 1200 & 1.7 & 0.06 & 0.07 & 0.07 & & $12 \%(\mathrm{SL})$ & 0.24 & \\
\hline
\end{tabular}

${ }^{1}$ (A) No gastric dissolution, (B) using bulk $\mathrm{pH}$, and (C) using $\mathrm{pH}_{\text {surface }}$ and $\mathrm{pH}_{\mathrm{eq}}$; ${ }^{2}$ The parentheses indicate the limiting factor of gastric dissolution; ${ }^{3}$ This in vivo Fa value could be an underestimated value due to steep nonlinearity in intestinal metabolism [91]. 

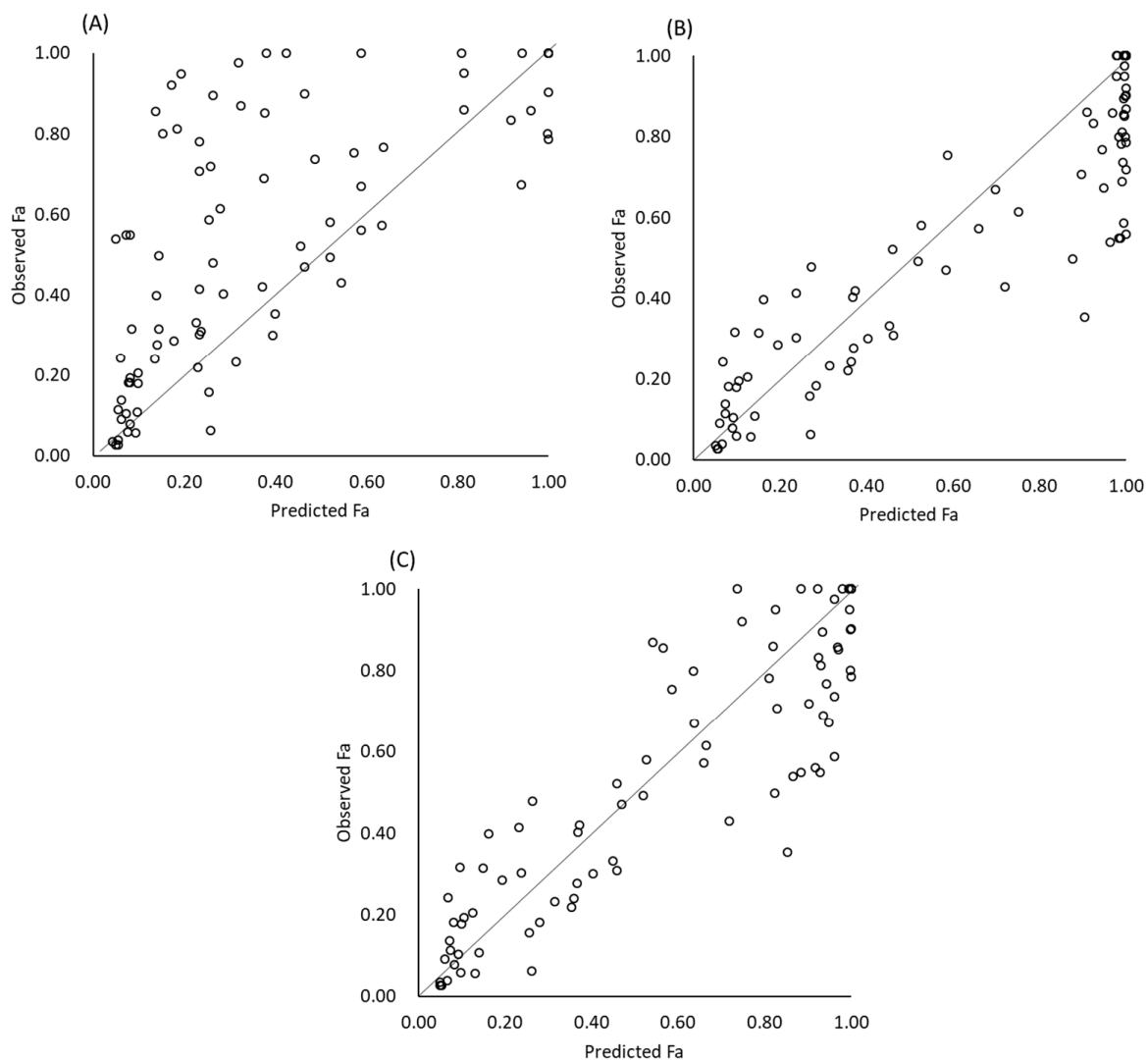

Figure 1. Predicted and observed Fa. (A) No gastric dissolution, (B) using bulk $\mathrm{pH}$, and (C) using $\mathrm{pH}_{\text {surface }}$ and $\mathrm{pH}_{\mathrm{eq}}$.

Table 4. Statistics of Fa prediction.

\begin{tabular}{|c|c|c|c|}
\hline \multirow{2}{*}{ Statistics } & \multicolumn{3}{|l|}{ Prediction Scenario $^{1}$} \\
\hline & (A) No Gastric Dissolution & (B) Bulk pH & (C) $\mathrm{pH}_{\mathrm{eq}} / \mathrm{pH}_{\text {surface }}$ \\
\hline \multicolumn{4}{|l|}{ All drug } \\
\hline $\mathrm{N}$ & 85 & 85 & 85 \\
\hline AAFE & 1.85 & 1.41 & 1.40 \\
\hline AFE & 0.64 & 1.10 & 1.04 \\
\hline $\mathrm{r}^{2}$ & 0.47 & 0.83 & 0.79 \\
\hline $\begin{array}{l}\% \text { within } 2 \text {-fold } \\
\text { error }\end{array}$ & 64 & 89 & 91 \\
\hline \multicolumn{4}{|c|}{ Without posaconazole } \\
\hline $\mathrm{N}$ & 69 & 69 & 69 \\
\hline AAFE & 1.87 & 1.37 & 1.36 \\
\hline AFE & 0.64 & 1.23 & 1.15 \\
\hline $\mathrm{r}^{2}$ & 0.43 & 0.83 & 0.78 \\
\hline $\begin{array}{l}\% \text { within } 2 \text {-fold } \\
\text { error }\end{array}$ & 65 & 93 & 94 \\
\hline
\end{tabular}

${ }^{1}$ (A) No gastric dissolution, (B) using bulk $\mathrm{pH}$, and (C) using $\mathrm{pH}_{\text {surface }}$ and $\mathrm{pH}_{\mathrm{eq}}$.

\subsection{Prediction of Drug-Drug Interaction (DDI) with Acid-Reducing Agents (ARA)}

The effect of the ARA (AUCr) was also appropriately predicted by scenario (C) (AAFE $=1.54$, $\mathrm{AFE}=1.04, \mathrm{r}^{2}=0.73, \%$ within 2 -fold error $=82 \%$ ) (Figure 2$)$. When gastric dissolution was limited by the dissolution rate (DRL), the drug tended to show marked AUC reduction by ARA DDI ( $>30 \%$ reduction in all DRL cases). In the case when gastric dissolution was solubility-limited (SL), the contribution of gastric dissolution on Fa became small, and therefore, ARA DDI became less significant. 


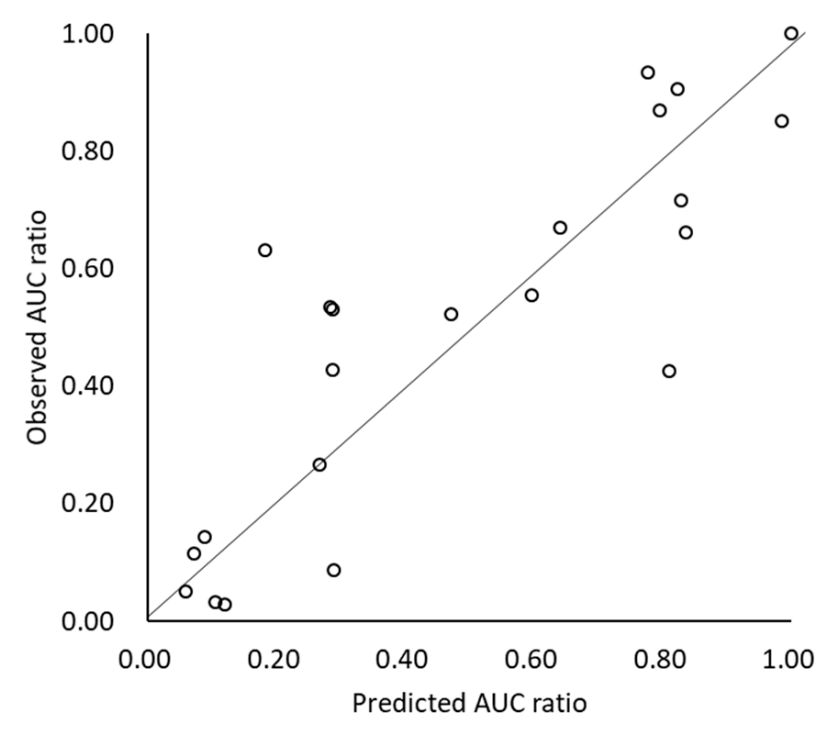

Figure 2. Predicted and observed AUCr with/without ARA.

\section{Discussion}

In this study, a simple model equation describing the gastric dissolution processes was introduced for the first time. By using this modeling strategy, both Fa and AUCr of free weak base drugs were successfully predicted in a bottom-up manner from the intrinsic drug parameters and physiological parameters. The Fa predictability observed in this study (AAFE $=1.40, \mathrm{AFE}=1.04$ ) was similar to the previously reported values for neutral and free acid drugs (AAFE $=1.46, \mathrm{AFE}=0.95$ ) [35]. This good predictability suggests that the simple $\mathrm{Fd}_{\mathrm{ST}}$ and $\mathrm{Fa}$ models appropriately capture the essence of oral drug absorption. The results of this study suggest that, instead of using the bulk $\mathrm{pH}, \mathrm{pH}_{\mathrm{eq}}$ and $\mathrm{pH}_{\text {surface }}$ should be used so as not to overestimate gastric dissolution. In many cases, gastric $\mathrm{pH}$ was predicted to be increased from the initial value of $\mathrm{pH} 2.0$ to above $\mathrm{pH} 3.0$ by dissolving free base molecules (Supplementary Material 3). In addition, the surface $\mathrm{pH}$ was also predicted to be increased to above pH 3.0 in many cases. A difference of 1 unit of $\mathrm{pH}$ corresponds to a 10-fold difference in solubility and dissolution rates. Therefore, it is important to consider $\mathrm{pH}_{\mathrm{eq}}$ and $\mathrm{pH}_{\text {surface }}$ when simulating the gastric dissolution of free weak base drugs.

However, even when using $\mathrm{pH}_{\mathrm{eq}}$ and $\mathrm{pH}_{\text {surface, }}$, the Fa values of aprepitant $(100 \mathrm{mg}, 5 \mu \mathrm{m})$, cinnarizine, danixirin, and dipyridamole were slightly overestimated (1.6-, 1.4-, 1.6-, and 1.7-fold, respectively), probably because particle growth and precipitation in the small intestine were neglected. This overestimation is in good agreement with the previous modeling study [26], in which particle growth in the small intestine was considered.

In the case of free weak base drugs, some portion of drug particles would remain undissolved in the stomach and reach the small intestine. These particles can serve as seed particles for particle growth, which reduces dissolved drug concentration in the small intestine [25,26]. However, Koyama et al. reported that the effect of seed particles can be less significant in some drugs [29]. In addition, the rate of concentration reduction became slower as the size of the seed particles became larger [29]. In the case of high permeability drugs, the intestinal permeation rate can be faster than the particle growth rate [92]. Most of the model drugs of this study are lipophilic, so that they can rapidly permeate the intestinal membrane. Therefore, for lipophilic drugs, particle growth in the small intestine may only have a slight effect on Fa.

The drug concentration in the small intestine can also be reduced by precipitation via nucleation without seed particles. However, direct clinical observation suggested that precipitation in the small intestine was minimal (dipyridamole, $\leq 7 \%$ ) or limited (ketoconazole, $\leq 16 \%$ ) after solution administration [93]. In addition, rapid intestinal absorption reduces supersaturation and prevents 
rapid precipitation in the small intestine [94-96]. Furthermore, in vivo intestinal fluid components such as mucus can inhibit drug precipitation [97]. Taken together, in the case of free weak base drugs, it can be a good approximation to neglect particle growth and precipitation. However, intestinal precipitation could be significant for salt form drugs because it can induce higher supersaturation than free form drugs [98]. Another possible reason for overestimation is a deviation from the theoretical $\mathrm{pH}$-solubility profile. The predicted solubility value of cinnarizine at $\mathrm{pH}_{\text {surface }}(11 \mathrm{mg} / \mathrm{mL}$ at $\mathrm{pH} 2.6)$ is about 7-fold higher than the experimental value $(1.5 \mathrm{mg} / \mathrm{mL}$ at $\mathrm{pH} 2.5)$ [99]. The $\mathrm{pH}$-solubility profile of cinnarizine suggested that this is not due to the common ionic effect [99].

In this study, the Fa values of high dose posaconazole were two to threefold underestimated. The reason is not clear. Previously, Hens et al. reported that after intragastric administration of posaconazole ( $40 \mathrm{mg}, 1 / 10$ of clinical dose) as acidified suspension ( $\mathrm{pH} \mathrm{1.6,240} \mathrm{mL,} \mathrm{76 \%} \mathrm{in} \mathrm{solution),}$ supersaturation was observed for $45 \mathrm{~min}$. However, when administered as an unbuffered suspension in tap water ( $\mathrm{pH} 7.1,240 \mathrm{~mL}$ ), no supersaturation was observed [100]. In the present study, at the clinical doses of 200 and $400 \mathrm{mg}$, less than $10 \%$ was predicted to be dissolved in the stomach. Therefore, the small intestinal process may be the reason for the underestimation.

The simple "bottom-up" modeling strategy employed in this study is suitable for use in drug discovery, where available input data are limited. Because particle growth in the small intestine is neglected, the predicted Fa value should be interpreted as a possible maximum Fa value. In addition, the predicted AUCr value should also be considered as a worst-case scenario. This predictive property is rather preferable to avoid false-negative DDI predictions. Another advantage of this simple modeling strategy is that it can provide insight into the rate-limiting step of gastric dissolution. The gastric dissolution can be diagnosed as SL and DRL by Equation (14). In addition, the contribution of gastric dissolution on Fa can be estimated by Equation (16). This information is important for formulation design. In addition, because simple analytical solutions enable tracing calculations and improve transparency, this modeling strategy is also suitable for regulatory submission.

For more accurate prediction, a complicated numerical simulation might be required to describe particle dissolution in the stomach, particle transit from the stomach to the small intestine, and particle growth and redissolution in the small intestine. Previously, it was suggested that the Fa values of dipyridamole could be more appropriately predicted when particle growth in the small intestine was considered [26]. Systematic validation of the GUT framework with dynamic simulation is under investigation and will be published elsewhere. Commercial software products such as GastroPlus ${ }^{\mathrm{TM}}$ and SimCYP ${ }^{\circledR}$ can also handle gastric dissolution processes [20]. The predictability of these software products should be systematically evaluated before they are used for regulatory purposes [35]. In this study, nearly $100 \mathrm{Fa}$ and AUCr values were compiled from the literature. These datasets would be an asset for the evaluation of simulation models in the future. The predictability of the simple analytical solution in this study will serve as a benchmark for assessing the prediction skills of more complex prediction models [35]. It should be noted that the good descriptive power of a complex model does not necessarily imply its good predictive skills. The prediction skill of a model should be carefully investigated before using the model in drug discovery and development.

\section{Conclusions}

In this study, the bottom-up modeling strategy to predict the Fa values of free weak base drugs was systematically evaluated. By considering gastric dissolution, the in vivo Fa values were appropriately predicted $(\mathrm{AAFE}=1.40, \mathrm{AFE}=1.04$ ). In addition, the AUC ratios with/without ARA were also appropriately predicted $(\mathrm{AAFE}=1.54$, AFE $=1.04)$. The Fa predictability confirmed in this study is comparable with that previously reported for neutral and free acid drugs (AAFE $=1.46$, AFE $=0.95)$ [35]. The modeling strategy employed in this study will be of great importance for drug discovery and development. 
Supplementary Materials: The following are available online at http://www.mdpi.com/1999-4923/12/9/0844/s1, Supplementary Material 1: The GUT framework for Fa ${ }_{S I}$ calculation, Supplementary Material 2: In vivo Fa values and references, Supplementary Material 3: Intermediate calculation parameters.

Author Contributions: Conceptualization, N.M. and K.S.; Data curation, N.M., A.O., Y.A. and K.S.; Formal analysis, N.M., A.O., Y.A. and K.S.; Investigation, N.M., A.O., Y.A. and K.S.; Methodology, N.M., A.O., Y.A. and K.S.; Project administration, N.M. and T.F.; Resources, T.F.; Software, K.S.; Supervision, T.F. and K.S.; Validation, N.M., A.O., Y.A. and K.S.; Visualization, N.M. and K.S.; Writing-original draft, N.M. and K.S.; Writing-review and editing, N.M., A.O., Y.A., T.F. and K.S. All authors have read and agreed to the published version of the manuscript.

Funding: This research received no external funding. The APC was funded by Ono Pharmaceutical Co., Ltd.

Acknowledgments: This study was conducted under the Consortium of Biopharmaceutical Tools (CoBiTo) project in the Consortium of Pharmaceutical Technology, Research Center for Drug Discovery and Development Science at Ritsumeikan University. The authors would like to thank all CoBiTo members for their supports. The CoBiTo members are Asahi Kasei Pharma Corporation, Daiichi Sankyo Company, Limited, Daiichi Sankyo RD Novare Co., Ltd., Japan Machinery Co., Ltd., Japan Tobacco Inc. (Pharmaceutical division), Mitsubishi Tanabe Pharma Corporation, Nippon Boehringer Ingelheim Co., Ltd., Ono Pharmaceutical Co., Ltd., Ritsumeikan University, Sawai Pharmaceutical Co., Ltd., Shionogi \& Co., Ltd., Sumitomo Dainippon Pharma Co., Ltd., and Towa Pharmaceutical Co., Ltd. (in alphabetical order).

Conflicts of Interest: Kiyohiko Sugano is the founder of BioavailabilityDesign LLC. Ono Pharmaceutical Co., Ltd. and BioavailabilityDesign LLC had no role in the design of the study; in the collection, analyses, or interpretation of data; in the writing of the manuscript, or in the decision to publish the results.

\section{References}

1. Thayer, A.M. Custom manufacturers take on DRUG SOLUBILITY ISSUES to help pharmaceutical firms move products through development. Chem. Eng. News 2010, 88, 13-18.

2. Sugano, K.; Okazaki, A.; Sugimoto, S.; Tavornvipas, S.; Omura, A.; Mano, T. Solubility and dissolution profile assessment in drug discovery. Drug Metab. Pharmacokinet. 2007, 22, 225-254.

3. Abrahamsson, B.; McAllister, M.; Augustijns, P.; Zane, P.; Butler, J.; Holm, R.; Langguth, P.; Lindahl, A.; Müllertz, A.; Pepin, X.; et al. Six years of progress in the oral biopharmaceutics area-A summary from the IMI OrBiTo project. Eur. J. Pharm. Biopharm. 2020, 152, 236-247.

4. Sugano, K. Introduction to computational oral absorption simulation. Expert Opin. Drug Metab. Toxicol. 2009, 5, 259-293.

5. Sugano, K. Biopharmaceutics Modeling and Simulations: Theory, Practice, Methods, and Applications; John Wiley \& Sons, Inc.: Hoboken, NJ, USA, 2012.

6. Budha, N.R.; Frymoyer, A.; Smelick, G.S.; Jin, J.Y.; Yago, M.R.; Dresser, M.J.; Holden, S.N.; Benet, L.Z.; Ware, J.A. Drug absorption interactions between oral targeted anticancer agents and PPIs: Is pH-dependent solubility the Achilles heel of targeted therapy? Clin. Pharmacol. Ther. 2012, 92, 203-213.

7. Indini, A.; Petrelli, F.; Tomasello, G.; Rijavec, E.; Facciorusso, A.; Grossi, F.; Ghidini, M. Impact of Use of Gastric-Acid Suppressants and Oral Anti-Cancer Agents on Survival Outcomes: A Systematic Review and Meta-Analysis. Cancers 2020, 12, 998.

8. $\quad$ Patel, D.; Bertz, R.; Ren, S.; Boulton, D.W.; Någård, M. A Systematic Review of Gastric Acid-Reducing Agent-Mediated Drug-Drug Interactions with Orally Administered Medications. Clin. Pharmacokinet. 2020, 59, 447-462.

9. Morihara, M.; Aoyagi, N.; Kaniwa, N.; Kojima, S.; Ogata, H. Assessment of gastric acidity of Japanese subjects over the last 15 years. Biol. Pharm. Bull. 2001, 24, 313-315.

10. Russell, T.L.; Berardi, R.R.; Barnett, J.L.; Dermentzoglou, L.C.; Jarvenpaa, K.M.; Schmaltz, S.P.; Dressman, J.B. Upper gastrointestinal pH in seventy-nine healthy, elderly, North American men and women. Pharm. Res. 1993, 10, 187-196.

11. van de Waterbeemd, H.; Gifford, E. ADMET in silico modelling: Towards prediction paradise? Nat. Rev. Drug Discov. 2003, 2, 192-204.

12. Arora, S.; Pansari, A.; Kilford, P.; Jamei, M.; Gardner, I.; Turner, D.B. Biopharmaceutic In Vitro In Vivo Extrapolation (IVIV_E) Informed Physiologically-Based Pharmacokinetic Model of Ritonavir Norvir Tablet Absorption in Humans Under Fasted and Fed State Conditions. Mol. Pharm. 2020, 17, 2329-2344. 
13. Kato, T.; Nakagawa, H.; Mikkaichi, T.; Miyano, T.; Matsumoto, Y.; Ando, S. Establishment of a clinically relevant specification for dissolution testing using physiologically based pharmacokinetic (PBPK) modeling approaches. Eur. J. Pharm. Biopharm. 2020, 151, 45-52.

14. Mitra, A.; Parrott, N.; Miller, N.; Lloyd, R.; Tistaert, C.; Heimbach, T.; Ji, Y.; Kesisoglou, F. Prediction of $\mathrm{pH}$-Dependent Drug-Drug Interactions for Basic Drugs Using Physiologically Based Biopharmaceutics Modeling: Industry Case Studies. J. Pharm. Sci. 2020, 109, 1380-1394.

15. Tistaert, C.; Heimbach, T.; Xia, B.; Parrott, N.; Samant, T.S.; Kesisoglou, F. Food Effect Projections via Physiologically Based Pharmacokinetic Modeling: Predictive Case Studies. J. Pharm. Sci. 2019, 108, 592-602.

16. Yu, Y.; DuBois, S.G.; Wetmore, C.; Khosravan, R. Physiologically Based Pharmacokinetic Modeling and Simulation of Sunitinib in Pediatrics. AAPS J. 2020, 22, 31.

17. Margolskee, A.; Darwich, A.S.; Pepin, X.; Pathak, S.M.; Bolger, M.B.; Aarons, L.; Rostami-Hodjegan, A.; Angstenberger, J.; Graf, F.; Laplanche, L.; et al. IMI-Oral biopharmaceutics tools project-Evaluation of bottom-up PBPK prediction success part 1: Characterisation of the OrBiTo database of compounds. Eur. J. Pharm. Sci. 2017, 96, 598-609.

18. Sjögren, E.; Thörn, H.; Tannergren, C. Reply to "Comment on 'In Silico Modeling of Gastrointestinal Drug Absorption: Predictive Performance of Three Physiologically Based Absorption Models'”. Mol. Pharm. 2017, 14, 340-343.

19. Li, M.; Zhao, P.; Pan, Y.; Wagner, C. Predictive Performance of Physiologically Based Pharmacokinetic Models for the Effect of Food on Oral Drug Absorption: Current Status. CPT Pharmacomet. Syst. Pharmacol. 2018, 7, $82-89$.

20. Dodd, S.; Kollipara, S.; Sanchez-Felix, M.; Kim, H.; Meng, Q.; Beato, S.; Heimbach, T. Prediction of ARA/PPI Drug-Drug Interactions at the Drug Discovery and Development Interface. J. Pharm. Sci. 2019, 108, 87-101.

21. Mooney, K.G.; Mintun, M.A.; Himmelstein, K.J.; Stella, V.J. Dissolution kinetics of carboxylic acids I: Effect of pH under unbuffered conditions. J. Pharm. Sci. 1981, 70, 13-22.

22. Ozturk, S.S.; Palsson, B.O.; Dressman, J.B. Dissolution of ionizable drugs in buffered and unbuffered solutions. Pharm. Res. 1988, 5, 272-282.

23. Pudipeddi, M.; Zannou, E.A.; Vasanthavada, M.; Dontabhaktuni, A.; Royce, A.E.; Joshi, Y.M.; Serajuddin, A.T. Measurement of surface $\mathrm{pH}$ of pharmaceutical solids: A critical evaluation of indicator dye-sorption method and its comparison with slurry pH method. J. Pharm. Sci. 2008, 97, 1831-1842.

24. Serajuddin, A.T.; Jarowski, C.I. Effect of diffusion layer $\mathrm{pH}$ and solubility on the dissolution rate of pharmaceutical bases and their hydrochloride salts. I: Phenazopyridine. J. Pharm. Sci. 1985, 74, 142-147.

25. Johnson, K.C. Dissolution and absorption modeling: Model expansion to simulate the effects of precipitation, water absorption, longitudinally changing intestinal permeability, and controlled release on drug absorption. Drug Dev. Ind. Pharm. 2003, 29, 833-842.

26. Sugano, K. Computational oral absorption simulation of free base drugs. Int. J. Pharm. 2010, 398, 73-82.

27. Serajuddin, A.T. Salt formation to improve drug solubility. Adv. Drug Deliv. Rev. 2007, 59, 603-616.

28. Sugano, K. A simulation of oral absorption using classical nucleation theory. Int. J. Pharm. 2009, 378, 142-145.

29. Koyama, H.; Ito, M.; Terada, K.; Sugano, K. Effect of Seed Particles on Precipitation of Weak Base Drugs in Physiological Intestinal Conditions. Mol. Pharm. 2016, 13, 2711-2717.

30. Oki, J.; Watanabe, D.; Uekusa, T.; Sugano, K. Mechanism of Supersaturation Suppression in Dissolution Process of Acidic Drug Salt. Mol. Pharm. 2019, 16, 1669-1677.

31. Omori, M.; Uekusa, T.; Oki, J.; Inoue, D.; Sugano, K. Solution-mediated phase transformation at particle surface during cocrystal dissolution. J. Drug Deliv. Sci. Technol. 2020, 56, 101566.

32. Uekusa, T.; Oki, J.; Omori, M.; Watanabe, D.; Inoue, D.; Sugano, K. Effect of buffer capacity on dissolution and supersaturation profiles of pioglitazone hydrochloride. J. Drug Deliv. Sci. Technol. 2019, 55, 101492.

33. Uekusa, T.; Sugano, K. Effect of buffer capacity on dissolution and supersaturation profiles of poorly soluble drug salt. In Proceedings of the APSTJ Annual Meeting, Toyama, Japan, 16-18 May 2019; p. 236.

34. Akiyama, Y.; Kimoto, T.; Mukumoto, H.; Miyake, S.; Ito, S.; Taniguchi, T.; Nomura, Y.; Matsumura, N.; Fujita, T.; Sugano, K. Prediction Accuracy of Mechanism-Based Oral Absorption Model for Dogs. J. Pharm. Sci. 2019, 108, 2728-2736.

35. Matsumura, N.; Hayashi, S.; Akiyama, Y.; Ono, A.; Funaki, S.; Tamura, N.; Kimoto, T.; Jiko, M.; Haruna, Y.; Sarashina, A.; et al. Prediction Characteristics of Oral Absorption Simulation Software Evaluated Using Structurally Diverse Low-Solubility Drugs. J. Pharm. Sci. 2020, 109, 1403-1416. 
36. Sugano, K. Fraction of a dose absorbed estimation for structurally diverse low solubility compounds. Int. J. Pharm. 2011, 405, 79-89.

37. Vertzoni, M.; Pastelli, E.; Psachoulias, D.; Kalantzi, L.; Reppas, C. Estimation of intragastric solubility of drugs: In what medium? Pharm. Res. 2007, 24, 909-917.

38. Sugano, K. Calculation of fraction of dose absorbed: Comparison between analytical solution based on one compartment steady state concentration approximation and dynamic seven compartment model. CBI J. 2009, 9, 75-93.

39. Grimm, M.; Koziolek, M.; Kühn, J.P.; Weitschies, W. Interindividual and intraindividual variability of fasted state gastric fluid volume and gastric emptying of water. Eur. J. Pharm. Biopharm. 2018, 127, 309-317.

40. Grimm, M.; Scholz, E.; Koziolek, M.; Kühn, J.P.; Weitschies, W. Gastric Water Emptying under Fed State Clinical Trial Conditions Is as Fast as under Fasted Conditions. Mol. Pharm. 2017, 14, 4262-4271.

41. Koziolek, M.; Grimm, M.; Garbacz, G.; Kühn, J.P.; Weitschies, W. Intragastric volume changes after intake of a high-caloric, high-fat standard breakfast in healthy human subjects investigated by MRI. Mol. Pharm. 2014, 11, 1632-1639.

42. McConnell, E.L.; Fadda, H.M.; Basit, A.W. Gut instincts: Explorations in intestinal physiology and drug delivery. Int. J. Pharm. 2008, 364, 213-226.

43. Mudie, D.M.; Amidon, G.L.; Amidon, G.E. Physiological parameters for oral delivery and in vitro testing. Mol. Pharm. 2010, 7, 1388-1405.

44. Shingaki, T.; Takashima, T.; Wada, Y.; Tanaka, M.; Kataoka, M.; Ishii, A.; Shigihara, Y.; Sugiyama, Y.; Yamashita, S.; Watanabe, Y. Imaging of gastrointestinal absorption and biodistribution of an orally administered probe using positron emission tomography in humans. Clin. Pharmacol. Ther. 2012, 91, 653-659.

45. Ehrlein, H.J.; Pröve, J. Effect of viscosity of test meals on gastric emptying in dogs. Q. J. Exp. Physiol. 1982, 67, 419-425.

46. Gupta, P.K.; Robinson, J.R. Gastric emptying of liquids in the fasted dog. Int. J. Pharm. 1988, 43, 45-52.

47. Mizuta, H.; Kawazoe, Y.; Haga, K.; Ogawa, K. Effects of meals on gastric emptying and small intestinal transit times of a suspension in the beagle dog assessed using acetaminophen and salicylazosulfapyridine as markers. Chem. Pharm. Bull. 1990, 38, 2224-2227.

48. Wyse, C.A.; McLellan, J.; Dickie, A.M.; Sutton, D.G.; Preston, T.; Yam, P.S. A review of methods for assessment of the rate of gastric emptying in the dog and cat: 1898-2002. J. Vet. Intern. Med. 2003, 17, 609-621.

49. Wang, C.; Zhai, B.; Guo, H.; Wang, P.; Liu, Z.; Gu, H.; Ho, H.; Langguth, P.; Li, K.; Wang, C.; et al. In vivo measurement of gastric fluid volume in anesthetized dogs. J. Drug Deliv. Sci. Technol. 2020, 55, 101488.

50. Martinez, M.N.; Papich, M.G. Factors influencing the gastric residence of dosage forms in dogs. J. Pharm. Sci. 2009, 98, 844-860.

51. Wu, Y.; Loper, A.; Landis, E.; Hettrick, L.; Novak, L.; Lynn, K.; Chen, C.; Thompson, K.; Higgins, R.; Batra, U.; et al. The role of biopharmaceutics in the development of a clinical nanoparticle formulation of MK-0869: A Beagle dog model predicts improved bioavailability and diminished food effect on absorption in human. Int. J. Pharm. 2004, 285, 135-146.

52. Zollers, B.; Rhodes, L.; Heinen, E. Capromorelin oral solution (ENTYCE ${ }^{\circledR}$ ) increases food consumption and body weight when administered for 4 consecutive days to healthy adult Beagle dogs in a randomized, masked, placebo controlled study. BMC Vet. Res. 2017, 13, 10.

53. Dressman, J.B.; Berardi, R.R.; Dermentzoglou, L.C.; Russell, T.L.; Schmaltz, S.P.; Barnett, J.L.; Jarvenpaa, K.M. Upper gastrointestinal (GI) pH in young, healthy men and women. Pharm. Res. 1990, 7, 756-761.

54. Fletcher, J.; Wirz, A.; Young, J.; Vallance, R.; McColl, K.E. Unbuffered highly acidic gastric juice exists at the gastroesophageal junction after a meal. Gastroenterology 2001, 121, 775-783.

55. Dressman, J.B. Comparison of canine and human gastrointestinal physiology. Pharm. Res. 1986, 3, $123-131$.

56. Sagawa, K.; Li, F.; Liese, R.; Sutton, S.C. Fed and fasted gastric $\mathrm{pH}$ and gastric residence time in conscious beagle dogs. J. Pharm. Sci. 2009, 98, 2494-2500.

57. Akimoto, M.; Nagahata, N.; Furuya, A.; Fukushima, K.; Higuchi, S.; Suwa, T. Gastric pH profiles of beagle dogs and their use as an alternative to human testing. Eur. J. Pharm. Biopharm. 2000, 49, 99-102.

58. Koziolek, M.; Grimm, M.; Bollmann, T.; Schäfer, K.J.; Blattner, S.M.; Lotz, R.; Boeck, G.; Weitschies, W. Characterization of the GI transit conditions in Beagle dogs with a telemetric motility capsule. Eur. J. Pharm. Biopharm. 2019, 136, 221-230. 
59. Polentarutti, B.; Albery, T.; Dressman, J.; Abrahamsson, B. Modification of gastric $\mathrm{pH}$ in the fasted dog. J. Pharm. Pharmacol. 2010, 62, 462-469.

60. Castell, D.; Bagin, R.; Goldlust, B.; Major, J.; Hepburn, B. Comparison of the effects of immediate-release omeprazole powder for oral suspension and pantoprazole delayed-release tablets on nocturnal acid breakthrough in patients with symptomatic gastro-oesophageal reflux disease. Aliment. Pharmacol. Ther. 2005, 21, 1467-1474.

61. Miner, P.B., Jr.; Allgood, L.D.; Grender, J.M. Comparison of gastric pH with omeprazole magnesium $20.6 \mathrm{mg}$ (Prilosec OTC) o.m. famotidine $10 \mathrm{mg}$ (Pepcid AC) b.d. and famotidine $20 \mathrm{mg}$ b.d. over 14 days of treatment. Aliment. Pharmacol. Ther. 2007, 25, 103-109.

62. Kalantzi, L.; Persson, E.; Polentarutti, B.; Abrahamsson, B.; Goumas, K.; Dressman, J.B.; Reppas, C. Canine intestinal contents vs. simulated media for the assessment of solubility of two weak bases in the human small intestinal contents. Pharm. Res. 2006, 23, 1373-1381.

63. Takano, R.; Sugano, K.; Higashida, A.; Hayashi, Y.; Machida, M.; Aso, Y.; Yamashita, S. Oral absorption of poorly water-soluble drugs: Computer simulation of fraction absorbed in humans from a miniscale dissolution test. Pharm. Res. 2006, 23, 1144-1156.

64. Chiou, W.L.; Jeong, H.Y.; Chung, S.M.; Wu, T.C. Evaluation of using dog as an animal model to study the fraction of oral dose absorbed of 43 drugs in humans. Pharm. Res. 2000, 17, 135-140.

65. Mitra, A.; Kesisoglou, F.; Beauchamp, M.; Zhu, W.; Chiti, F.; Wu, Y. Using absorption simulation and gastric $\mathrm{pH}$ modulated dog model for formulation development to overcome achlorhydria effect. Mol. Pharm. 2011, 8, 2216-2223.

66. Pepin, X.J.H.; Moir, A.J.; Mann, J.C.; Sanderson, N.J.; Barker, R.; Meehan, E.; Plumb, A.P.; Bailey, G.R.; Murphy, D.S.; Krejsa, C.M.; et al. Bridging in vitro dissolution and in vivo exposure for acalabrutinib. Part II. A mechanistic PBPK model for IR formulation comparison, proton pump inhibitor drug interactions, and administration with acidic juices. Eur. J. Pharm. Biopharm. 2019, 142, 435-448.

67. Ono, A.; Matsumura, N.; Kimoto, T.; Akiyama, Y.; Funaki, S.; Tamura, N.; Hayashi, S.; Kojima, Y.; Fushimi, M.; Sudaki, H.; et al. Harmonizing solubility measurement to lower inter-laboratory variance-Progress of consortium of biopharmaceutical tools (CoBiTo) in Japan. ADMET DMPK 2019, 7, 183.

68. Vogt, M.; Kunath, K.; Dressman, J.B. Dissolution improvement of four poorly water soluble drugs by cogrinding with commonly used excipients. Eur. J. Pharm. Biopharm. 2008, 68, 330-337.

69. Andersson, S.B.E.; Alvebratt, C.; Bevernage, J.; Bonneau, D.; da Costa Mathews, C.; Dattani, R.; Edueng, K.; He, Y.; Holm, R.; Madsen, C.; et al. Interlaboratory Validation of Small-Scale Solubility and Dissolution Measurements of Poorly Water-Soluble Drugs. J. Pharm. Sci. 2016, 105, 2864-2872.

70. Parrott, N.; Lukacova, V.; Fraczkiewicz, G.; Bolger, M.B. Predicting pharmacokinetics of drugs using physiologically based modeling-Application to food effects. AAPS J. 2009, 11, 45-53.

71. Takano, R.; Furumoto, K.; Shiraki, K.; Takata, N.; Hayashi, Y.; Aso, Y.; Yamashita, S. Rate-limiting steps of oral absorption for poorly water-soluble drugs in dogs; prediction from a miniscale dissolution test and a physiologically-based computer simulation. Pharm. Res. 2008, 25, 2334-2344.

72. Gesenberg, C.; Mathias, N.R.; Xu, Y.; Crison, J.; Savant, I.; Saari, A.; Good, D.J.; Hemenway, J.N.; Narang, A.S.; Schartman, R.R.; et al. Utilization of In Vitro, In Vivo and In Silico Tools to Evaluate the pH-Dependent Absorption of a BCS Class II Compound and Identify a pH-Effect Mitigating Strategy. Pharm. Res. 2019, 36,164 .

73. Fagerberg, J.H.; Tsinman, O.; Sun, N.; Tsinman, K.; Avdeef, A.; Bergstrom, C.A. Dissolution rate and apparent solubility of poorly soluble drugs in biorelevant dissolution media. Mol. Pharm. 2010, 7, 1419-1430.

74. Bloomer, J.C.; Ambery, C.; Miller, B.E.; Connolly, P.; Garden, H.; Henley, N.; Hodnett, N.; Keel, S.; Kreindler, J.L.; Lloyd, R.S.; et al. Identification and characterisation of a salt form of Danirixin with reduced pharmacokinetic variability in patient populations. Eur. J. Pharm. Biopharm. 2017, 117, 224-231.

75. Dasatinib Drug Information. Available online: https://www.info.pmda.go.jp/go/pack/4291020F1027_1_15/ (accessed on 9 August 2020).

76. Vaidhyanathan, S.; Wang, X.; Crison, J.; Varia, S.; Gao, J.Z.H.; Saxena, A.; Good, D. Bioequivalence Comparison of Pediatric Dasatinib Formulations and Elucidation of Absorption Mechanisms Through Integrated PBPK Modeling. J. Pharm. Sci. 2019, 108, 741-749.

77. Avdeef, A. Absorption and Drug Development: Solubility, Permeability, and Charge State, 2nd ed.; John Wiley \& Sons, Inc.: Hoboken, NJ, USA, 2012. 
78. Ross, D.L.; Riley, C.M. Aqueous solubilities of some variously substituted quinolone antimicrobials. Int. J. Pharm. 1990, 63, 237-250.

79. Völgyi, G.; Vizserálek, G.; Takács-Novák, K.; Avdeef, A.; Tam, K.Y. Predicting the exposure and antibacterial activity of fluoroquinolones based on physicochemical properties. Eur. J. Pharm. Sci. 2012, 47, 21-27.

80. Okumu, A.; DiMaso, M.; Löbenberg, R. Computer simulations using GastroPlus to justify a biowaiver for etoricoxib solid oral drug products. Eur. J. Pharm. Biopharm. 2009, 72, 91-98.

81. Wilson, C.G.; O’Mahony, B.; Connolly, S.M.; Cantarini, M.V.; Farmer, M.R.; Dickinson, P.A.; Smith, R.P.; Swaisland, H.C. Do gastrointestinal transit parameters influence the pharmacokinetics of gefitinib? Int. J. Pharm. 2009, 376, 7-12.

82. de Zwart, L.; Snoeys, J.; De Jong, J.; Sukbuntherng, J.; Mannaert, E.; Monshouwer, M. Ibrutinib Dosing Strategies Based on Interaction Potential of CYP3A4 Perpetrators Using Physiologically Based Pharmacokinetic Modeling. Clin. Pharmacol. Ther. 2016, 100, 548-557.

83. Shi, X.; Song, S.; Ding, Z.; Fan, B.; Xu, T.; Huang, W. Improving the Solubility and Dissolution of Ibrutinib by Preparing Solvates. J. Pharm. Innov. 2019.

84. Palbociclib PMDA Approval Document. Available online: https://www.pmda.go.jp/drugs/2017/P20170830001/ (accessed on 9 August 2020).

85. Ibrahim, F.M.L.; Mullarney, M.P.; Shanker, R.M.; Spong, B.R.; Wang, J. Solid Dosage Forms of. Palbociclib. Patent WO2016193860A1, 8 December 2016.

86. Sun, W.; Klamerus, K.J.; Yuhas, L.M.; Pawlak, S.; Plotka, A.; O'Gorman, M.; Kirkovsky, L.; Kosa, M.; Wang, D. Impact of Acid-Reducing Agents on the Pharmacokinetics of Palbociclib, a Weak Base With pH-Dependent Solubility, With Different Food Intake Conditions. Clin. Pharmacol. Drug Dev. 2017, 6, 614-626.

87. Brouwers, J.; Pauwels, H.; Augustijns, P. In vitro evaluation of intestinal precipitation as a rate-limiting factor in fasted state absorption of posaconazole. In Proceedings of the AAPS Annual Meeting and Exposition, Washington, DC, USA, 23-27 October 2011.

88. Hens, B.; Pathak, S.M.; Mitra, A.; Patel, N.; Liu, B.; Patel, S.; Jamei, M.; Brouwers, J.; Augustijns, P.; Turner, D.B. In Silico Modeling Approach for the Evaluation of Gastrointestinal Dissolution, Supersaturation, and Precipitation of Posaconazole. Mol. Pharm. 2017, 14, 4321-4333.

89. Fossati, L.; Dechaume, R.; Hardillier, E.; Chevillon, D.; Prevost, C.; Bolze, S.; Maubon, N. Use of simulated intestinal fluid for Caco-2 permeability assay of lipophilic drugs. Int. J. Pharm. 2008, 360, 148-155.

90. Jantratid, E.; Janssen, N.; Reppas, C.; Dressman, J.B. Dissolution media simulating conditions in the proximal human gastrointestinal tract: An update. Pharm. Res. 2008, 25, 1663-1676.

91. Higashino, H.; Hasegawa, T.; Yamamoto, M.; Matsui, R.; Masaoka, Y.; Kataoka, M.; Sakuma, S.; Yamashita, S. In vitro-in vivo correlation of the effect of supersaturation on the intestinal absorption of BCS Class 2 drugs. Mol. Pharm. 2014, 11, 746-754.

92. Psachoulias, D.; Vertzoni, M.; Butler, J.; Busby, D.; Symillides, M.; Dressman, J.; Reppas, C. An in vitro methodology for forecasting luminal concentrations and precipitation of highly permeable lipophilic weak bases in the fasted upper small intestine. Pharm. Res. 2012, 29, 3486-3498.

93. Psachoulias, D.; Vertzoni, M.; Goumas, K.; Kalioras, V.; Beato, S.; Butler, J.; Reppas, C. Precipitation in and supersaturation of contents of the upper small intestine after administration of two weak bases to fasted adults. Pharm. Res. 2011, 28, 3145-3158.

94. Frank, K.J.; Locher, K.; Zecevic, D.E.; Fleth, J.; Wagner, K.G. In vivo predictive mini-scale dissolution for weak bases: Advantages of $\mathrm{pH}$-shift in combination with an absorptive compartment. Eur. J. Pharm. Sci. 2014, 61, 32-39.

95. Hate, S.S.; Reutzel-Edens, S.M.; Taylor, L.S. Absorptive Dissolution Testing of Supersaturating Systems: Impact of Absorptive Sink Conditions on Solution Phase Behavior and Mass Transport. Mol. Pharm. 2017, 14, 4052-4063.

96. Shi, Y.; Erickson, B.; Jayasankar, A.; Lu, L.; Marsh, K.; Menon, R.; Gao, P. Assessing Supersaturation and Its Impact on In Vivo Bioavailability of a Low-Solubility Compound ABT-072 With a Dual pH, Two-Phase Dissolution Method. J. Pharm. Sci. 2016, 105, 2886-2895.

97. Yeap, Y.Y.; Lock, J.; Lerkvikarn, S.; Semin, T.; Nguyen, N.; Carrier, R.L. Intestinal mucus is capable of stabilizing supersaturation of poorly water-soluble drugs. J. Controll. Release 2019, 296, 107-113. 
98. Kambayashi, A.; Yasuji, T.; Dressman, J.B. Prediction of the precipitation profiles of weak base drugs in the small intestine using a simplified transfer ("dumping") model coupled with in silico modeling and simulation approach. Eur. J. Pharm. Biopharm. 2016, 103, 95-103.

99. Tokumura, T.; Tsushima, Y.; Tatsuishi, K.; Kayano, M.; Machida, Y.; Nagai, T. Evaluation of bioavailability upon oral administration of cinnarizine-beta-cyclodextrin inclusion complex to beagle dogs. Chem. Pharm. Bull. 1985, 33, 2962-2967.

100. Hens, B.; Brouwers, J.; Corsetti, M.; Augustijns, P. Supersaturation and Precipitation of Posaconazole upon Entry in the Upper Small Intestine in Humans. J. Pharm. Sci. 2016, 105, 2677-2684.

(C) 2020 by the authors. Licensee MDPI, Basel, Switzerland. This article is an open access article distributed under the terms and conditions of the Creative Commons Attribution (CC BY) license (http://creativecommons.org/licenses/by/4.0/). 